\title{
Microstructural Evaluation of C-free Martensitic Alloys at High Temperatures
}

\author{
Katsumi YAMADA, Masaaki IGARASHI, ${ }^{1)}$ Seiichi MUNEKI, ${ }^{2)}$ Hirokazu OKADA ${ }^{2)}$ and Fujio ABE ${ }^{2)}$ \\ NKK, Minamiwatarida-cho, Kawasaki, Kanagawa 210-0855 Japan. \\ 1) Sumitomo Metal Industries, Ltd., Fuso-cho, \\ Amagasaki, Hyogo 660-0891 Japan. $\quad 2$ 2) National Institute for Materials Science, Sengen, Tsukuba, Ibaraki $305-0047$ \\ Japan.
}

(Received on January 9, 2002; accepted in final form on May 14, 2002)

\begin{abstract}
Microstructure of C-free martensitic alloys at elevated temperatures was studied for understanding the origin of their superior creep properties over $923 \mathrm{~K}$. These alloys initially have martensitic structure and the heterogeneous creep deformation seems to be suppressed even under low stress region in distinction from the conventional heat resisting steels because there is no rapid growth of carbides during creep at high temperatures.

Inter-metallic compounds such as Laves or $\mu$ phase were dominantly observed over $923 \mathrm{~K}$ and these precipitation had been followed by the low temperature reaction that greatly contributed to the typical aging behavior like in the usual maraging steels. It was found that the density of the precipitation was still kept high even at $973 \mathrm{~K}$ because its gathering and coalescence rate was small comparing with that of high $\mathrm{Cr}$ steels. Furthermore, the reversely transformed austenite phase certainly appeared by the shearing mechanism in these alloys when the materials were rapidly heated up to the temperature for creep testing, because their As points were measured to be at around $873 \mathrm{~K}$. This austenite phase represented terrace like feature in SEM observations. Fortunately, this characteristic structure was resulted from a selective electropolishing in specimen preparation due to the compositional fluctuation. However, it was also confirmed that partitioning of alloying element was not completed in the short-term aged materials.

It was concluded that the characteristic microstructure of these alloys over $923 \mathrm{~K}$ was continuously formed as follows. Firstly, uniform fine precipitation of inter-metallic compounds occurred at early stage and then the reversely transformed austenite was broken out without diffusion process. Finally, dissolution of precipitation in the retained martensitic region was assisted by long-term keeping at high temperatures. Consequently, it was expected that specific creep resistance of these alloys over $923 \mathrm{~K}$ be achieved by existence of large amount of austenitic phase strengthened by fine precipitation.
\end{abstract}

KEY WORDS: C-free; martensitic alloys; creep properties; maraging steels; precipitation; inter-metallic compound; reversely transformed austenite.

\section{Introduction}

It has been widely known that maraging steels have extremely high strength over $1300 \mathrm{MPa}$ by an appropriate aging procedure at around $773 \mathrm{~K}$ and they have been used for such as nose corn of rocket and accurate die assembly. Many studies have been carried on the remarkable aging behavior of these steels, for example, $\mathrm{Fe}-18 \mathrm{Ni}-9 \mathrm{Co}-5 \mathrm{Mo}-$ $\mathrm{Ti}, \mathrm{Al}$ (300 grade) since '60s. However, their microstructure and the related mechanical properties at temperatures over $873 \mathrm{~K}$ have not been well understood because these materials are not usually used at such high temperatures. Recently, we have been focusing on the creep properties of $\mathrm{C}$-free martensitic alloys based on the similar compositions of the maraging steels to explore suitable materials for ultra super critical power plant whose operating steam temperature is typically over $873 \mathrm{~K}$. Especially, we are interested in the characteristic creep deformation behavior mainly achieved by the stable microstructure of the alloys at elevated tem- peratures. This is a large advantage for the C-free martensitic alloys, since the conventional high-Cr heat resisting steels strengthened by carbides such as MX sometimes exhibit heterogeneous creep deformation due to the microstructural instability during long-term creep. By now, it is indicated that the creep properties of these new alloys over $923 \mathrm{~K}$ are superior to those of high $\mathrm{Cr}$ martensitic steels. $^{1-3)}$

Characteristic reverse transformation behavior of maraging steels and $\mathrm{Fe}-\mathrm{Ni}$ alloys have already been extensively studied by many researchers since $1969 .{ }^{4-8)}$ There is, however, few works done on the mechanical properties in relation to this transformation behavior. Moreover, systematic studies of microstructure correlated to high temperature creep properties of such alloys have never been done. Some alloys show better creep resistance than type 304 stainless steels over $973 \mathrm{~K}$ in the latest report ${ }^{3)}$ and then these alloys are regarded as one of the most likely candidate materials which compensate between stainless steels and $\mathrm{Ni}$ or $\mathrm{Co}-$ 
Table 1. Chemical compositions of alloys used (mass\%).

\begin{tabular}{|c|c|c|c|c|c|c|c|c|c|c|c|}
\hline alloys & Fe & $\mathrm{Ni}$ & $\mathrm{Co}$ & $\mathrm{Mo}$ & $\mathrm{W}$ & $\mathrm{Pd}$ & $\mathrm{B}$ & $\mathrm{Ti}$ & $\mathrm{Al}$ & $\mathrm{Si}$ & $\mathrm{Mn}$ \\
\hline $\mathrm{A}$ & bal. & 6.0 & 8.99 & 4.95 & 0 & 0 & 0.0052 & 0.21 & 0.087 & 0.02 & 0.46 \\
\hline B & bal. & 12.0 & 8.99 & 4.94 & 0 & 0 & 0.0048 & 0.18 & 0.085 & 0.01 & 0.45 \\
\hline C & bal. & 17.5 & 8.89 & 4.92 & 0 & 0 & 0.0050 & 0.18 & 0.071 & 0.01 & 0.45 \\
\hline D & bal. & 12.2 & 9.04 & 0 & 10.1 & 0 & 0.0050 & 0.20 & 0.088 & 0.01 & 0.47 \\
\hline E & bal. & 11.1 & 9.01 & 0 & 10.0 & 1.99 & 0.0049 & 0.18 & 0.10 & 0.02 & 0.46 \\
\hline
\end{tabular}

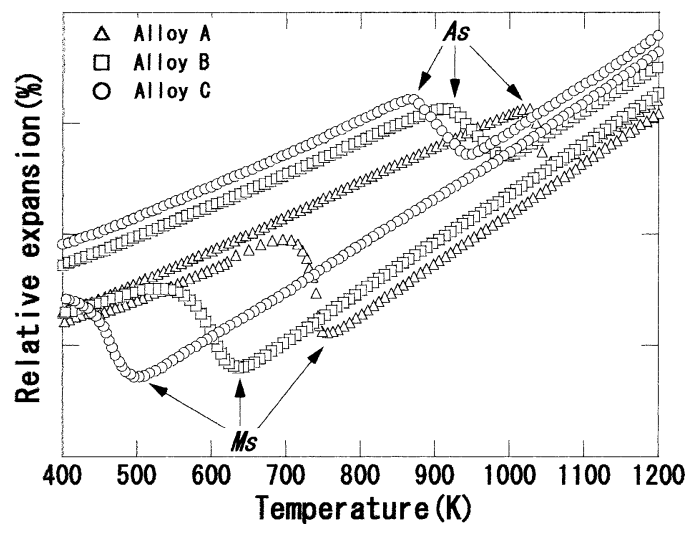

Fig. 1. The dilatometric behavior of the alloys A, B and C observed both on heating and cooling procedures.

based super alloys for the field of heat resisting materials.

In this work, the formation of microstructure in the Cfree martensitic alloys at high temperatures is studied especially focusing the transformation and precipitation behavior. Finally, creep-strengthening mechanism of this alloy system will be discussed.

\section{Experimental Procedure}

The chemical compositions of the materials used in this study are given in Table 1. Alloys A to $\mathrm{C}$ are Mo bearing $\mathrm{Fe}-\mathrm{Ni}-\mathrm{Co}$ alloys with changing $\mathrm{Ni}$ content and alloys $\mathrm{D}$ and $\mathrm{E}$ were $\mathrm{W}$ bearing $12 \mathrm{Ni}$-based alloys. $50 \mathrm{~kg}$ ingots were made using a vacuum induction furnace and $15 \mathrm{~mm}$ square bars were prepared with hot working followed by homogenization for $2 \mathrm{~h}$ at $1473 \mathrm{~K}$. All materials were used for study of transformation behavior and aging experiments after solution treatment for $0.5 \mathrm{~h}$ at $1273 \mathrm{~K}$. Measurement of transformation temperature was conducted by dilatometer (Fujidenpa; Formaster-F II) and differential scanning calorimeter, DSC (SETARAM; Labsys TMDSC12).

In order to clarify microstructure at high temperatures, aging was done for alloy $\mathrm{E}$ at $923 \mathrm{~K}$ and $973 \mathrm{~K}$ for 10,100 and $1000 \mathrm{~h}$. Microstructural evaluation was conducted by scanning electron microscope (Hitachi; S4700). Specimens for microscopy were prepared by electro-chemical polishing technique using a $10 \%$ perchloric acid ethanol solution. Transmission electron microscope was also used for studying a detailed microstructure with thin film specimens of aged materials.

\section{Results}

\subsection{Dilatometer and DSC}

Figure 1 shows the dilatometric behavior both on heating and cooling for alloys $\mathrm{A}, \mathrm{B}$ and $\mathrm{C}$ with changing $\mathrm{Ni}$ content. Heating rate is kept $10 \mathrm{~K} / \mathrm{s}$ in these measurements.
Table 2. Transformation temperatures determined by dilatometer (K).

\begin{tabular}{|c|c|c|c|c|}
\hline & Alloy A & Alloy B & Alloy C & Alloy D \\
\hline $\mathrm{A}_{\mathrm{s}}$ & 993 & 878 & 858 & 923 \\
\hline $\mathrm{A}_{\mathrm{f}}$ & 1103 & 1008 & 973 & 1063 \\
\hline $\mathrm{M}_{\mathrm{s}}$ & 798 & 658 & 523 & 633 \\
\hline $\mathrm{M}_{\mathrm{f}}$ & 653 & 488 & 453 & 530 \\
\hline
\end{tabular}
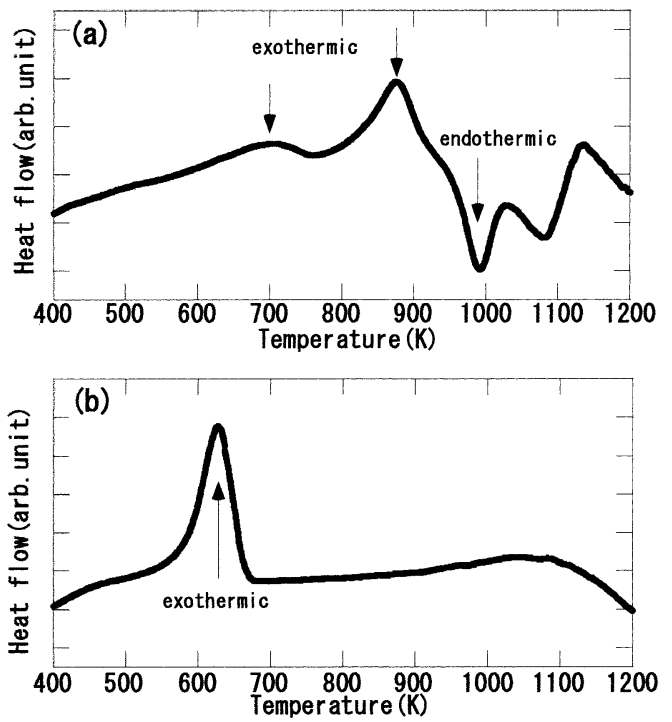

Fig. 2. DSC curves of the alloy B showing specific peaks corresponding the preciptiation and the transformation, (a) on heating and (b) on cooling.

There are clear two flexion points as indicated by arrows in all alloys. The first one represented by $A s$ corresponds to a start of volume contraction due to reverse transformation from initial martensite to austenite on heating process and second one, $M s$ corresponds to an expansion by martensitic transformation on cooling. It is also clear that $A s$ and $M S$ points are shifted to lower temperature range with increasing Ni content of alloys.

Table 2 summarizes transformation temperatures obtained by the measurements for these three alloys and alloy D. Figures 2(a) and 2(b) show the results of DSC experiment as represented for alloy B. In this measurement, heating rate is set $10 \mathrm{~K} / \mathrm{min}$, which is slower than that of the dilatometric experiment. On heating, a weak exothermic reaction from 623 to $773 \mathrm{~K}$ is detected followed by an second outstanding exothermic reaction around 850 to $900 \mathrm{~K}$ and a drastic endothermic reaction is observed over $900 \mathrm{~K}$. This sequential change in exothermic and endothermic reactions shown in Fig. 2(a) has been commonly observed in all the other alloys. On the other hand, only an abrupt exothermic peak is observed in the lower temperature range in a cooling curve as exemplified in Fig. 2(b). This reaction corresponds to the martensitic transformation of these alloy systems. 


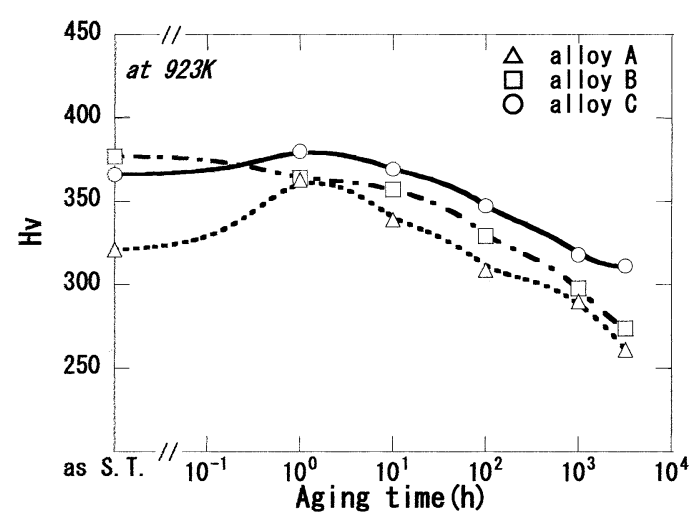

Fig. 3. Aging curves of the alloys A, B and C at $923 \mathrm{~K}$.
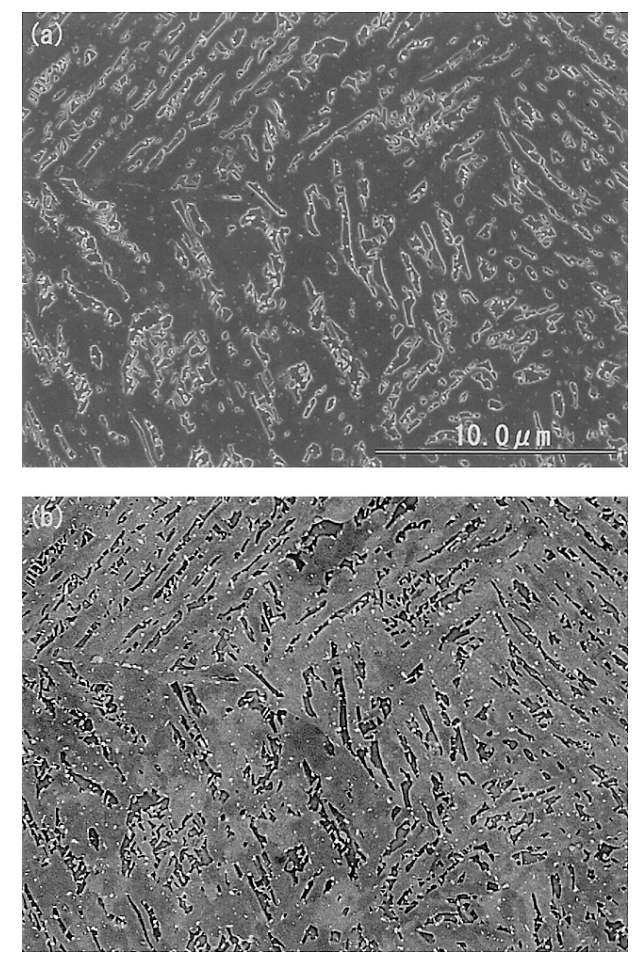

Fig. 4. Microstructures of the aged alloy B at $923 \mathrm{~K}$ for $1694 \mathrm{~h}$ showing the terrace-like matrix, (a) is a secondary electron image and (b) is a backscattered electron image, respecticely.

\subsection{Aging Behavior and Typical Microstructure}

These alloys initially have almost full martensitic structure transformed from super-cooled austenite after solution treatment. The initial hardness of the S.T. specimens is around $350 \mathrm{Hv}$, which is typical for a carbon free soft martensitic alloy. Figure 3 shows aging behavior of alloys $\mathrm{A}, \mathrm{B}$ and $\mathrm{C}$ at $923 \mathrm{~K}$. It is found that hardness level is kept high at early stage of aging but gradually decreased after $100 \mathrm{~h}$ probably due to recovery of martensite phase and coarsening of precipitates. However, hardness of prolonged aged materials is still kept at high level especially of alloy $\mathrm{C}$, which may be due to larger amounts of fresh martensite with increasing $\mathrm{Ni}$ content formed during cooling after aging at the temperature beyond $A s$ point.

Figures 4(a) and 4(b) represent the microstructure of an aged alloy B at $923 \mathrm{~K}$ for $1694 \mathrm{~h}$ using secondary electron and backscattered electron image of SEM, respectively. Microstructure within sub-micron order is clearly seen in
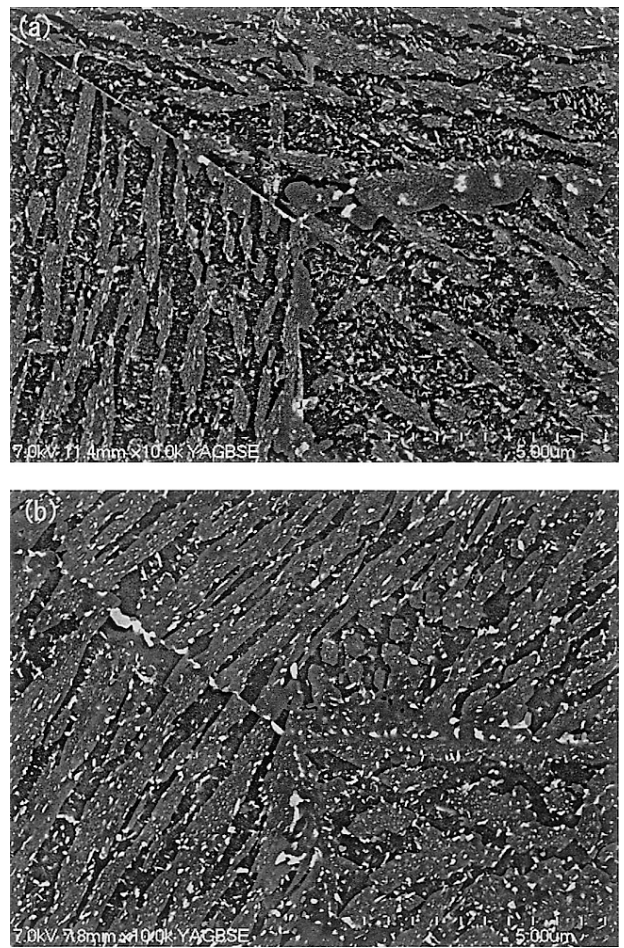

Fig. 5. Backscattered electron images of the alloy E, (a) is aged at $923 \mathrm{~K}$ and (b) is aged at $973 \mathrm{~K}$ for $100 \mathrm{~h}$, respectively.

Fig. 4(a) and existence of very fine precipitation is confirmed with high brightness in Fig. 4(b). The averaged size of precipitate is too small to be quantified by an SEM/EDX analysis, though it is expected that these are inter-metallic compounds such as Laves or $\mu$ phase because the concentration of Mo evaluated is higher than that of surrounding matrix. A complicated structure in matrix should be the evidence of the reverse transformation at $923 \mathrm{~K}$ in Alloy B. The electro-chemical polishing in specimen preparation often results in a selective polishing due to an elemental partitioning of different phases. It is supposed that an enhanced rugged surface structure in Fig. 4 is caused by mainly compositional change in Ni between the recovered ferrite and reverse transformed austenite region. In fact, a slight compositional fluctuation in $\mathrm{Ni}$ corresponding to this surface structure is observed in Ni mapping by SEM/EDX. We will call this specific morphology in matrix as a terrace structure at which weakly polished terraced region corresponds to Ni-rich austenite. It is also important that this austenite region has a similar contrast and an anisotropic feature within a prior-austenite grain in Fig. 4(b). This fact indicates that austenite has a specific crystallographic orientation with an untransformed martensitic region.

\subsection{Temperature and Time Dependence of Aged Microstructures}

In order to clarify the microstructural change during long-term aging at high temperatures like a creep testing, temperature and time dependences of the microstructures were studied using simple aged materials. Figures 5(a) and 5(b) show back scattered electron images of alloy $E$ which were aged at $923 \mathrm{~K}$ and $973 \mathrm{~K}$ for $100 \mathrm{~h}$, respectively. The triple point of prior-austenite grain boundary is located at the center of the field of view. Many fine precipitations 

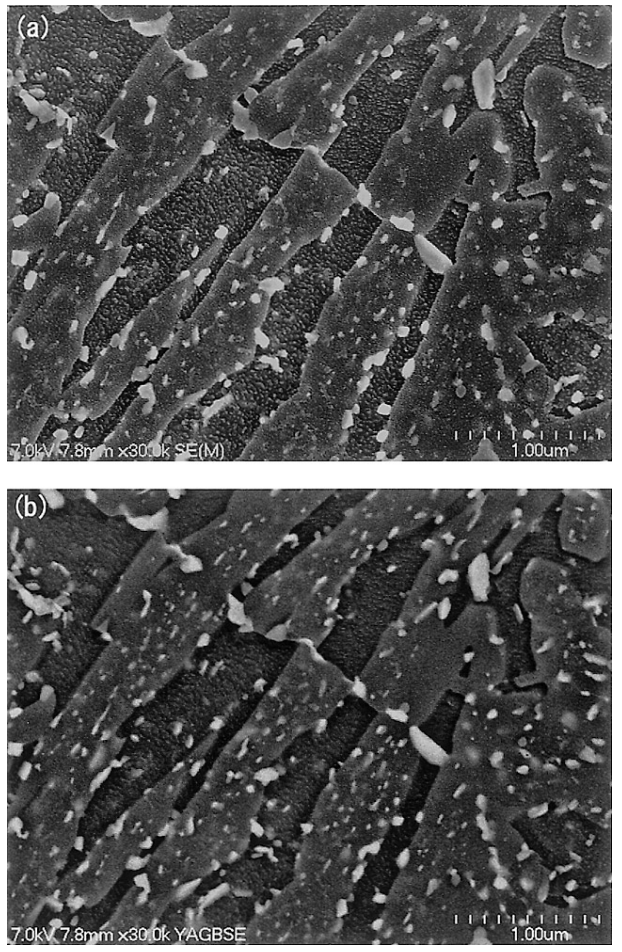

Fig. 6. High magnified SEM images of an aged alloys E at 973K, (a) is a secondary electron image and (b) is a backscattered electron image, respectively.

with extremely high brightness are observed in both specimens in addition to the specific terrace structure in matrix as described in Sec. 3.1. The fraction of terrace in matrix of Fig. 5(b) is larger than that of Fig. 5(a) because volume fraction of the transformed austenite phase certainly increases at higher temperature as will be demonstrated in the following discussion in Sec. 4.1.

Precipitate is typically large and blocky at prior-austenite grain boundaries in both specimens. Distribution of fine precipitates seems homogeneous in Fig. 5(a), however the frequency of the precipitates seems different between a terraced and a dented area in Fig. 5(b). Moreover, rapid coarsening of the precipitate is confirmed at the interface of the terrace structure. Figures 6(a) and 6(b) show high magnified images of an aged materials at $973 \mathrm{~K}$. The terrace structure in the matrix becomes clear and its terraced region contains many fine precipitates in it. On the other hand, the amount of the precipitate decreases in the dented area as clearly seen in Fig. 6(b) in which the contrast from fine precipitate is enhanced by atomic number effect on the yield of backscattered electrons.

Figures 7(a), 7(b) and 7(c) are the backscattered electron images showing microstructural change with aging time. Although the interface of the terrace structure as described is not yet clear for $10 \mathrm{~h}$-aged material, shown in Fig. 7(a), it becomes sharp at the aging time over $100 \mathrm{~h}$ as represented in Figs. 7(b) and 7(c). Precipitation in Fig. 7(a) is also not obvious but rather uniform in matrix region with the exception at prior-austenite grain boundaries. The frequency of the precipitates relatively increases at the interface of the terrace structure in Fig. 7(b) and extreme growth of an individual precipitation is observed in Fig. 7(c) especially at prior-austenite grain boundaries.
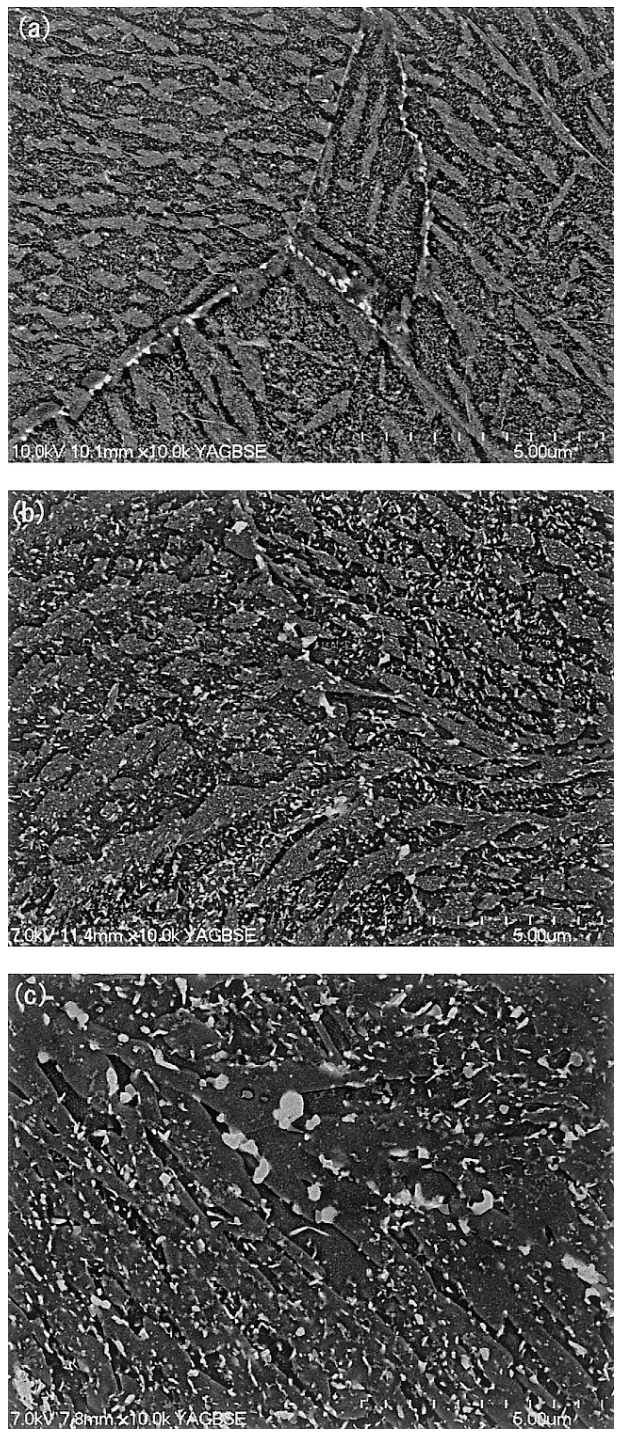

Fig. 7. Backscattered electron images of the alloy $\mathrm{E}$ with different aging time at $923 \mathrm{~K}$, (a) is $10 \mathrm{~h}$, (b) is $100 \mathrm{~h}$ and (c) is $1000 \mathrm{~h}$-aged.

\subsection{TEM Observation of Aged Materials}

In order to know the detailed behavior of a reverse transformation at elevated temperatures, TEM observation was conducted on alloy E aged at $923 \mathrm{~K}$. A uniform distribution of fine precipitation is observed within whole area in the material aged for $10 \mathrm{~h}$ as shown in Fig. 8. It is also confirmed that the partitioning of $\mathrm{Ni}$ is not so proceeded at this stage between the recovered ferrite and the martensitic area by using TEM/EDXS analysis. Contrary, characteristic thin specimen with non-uniform thickness is obtained by dominant selective polishing due to local elemental partitioning as shown in Fig. 9(a) for $100 \mathrm{~h}$-aged material. Thick area in Fig. 9(a) corresponds to a reversely transformed austenite region in which high dislocation density is kept. On the other hand, thin area is a recovered ferrite region at that temperature. In fact, Ni enrich is reproducibly detected at thick area by TEM/EDX analysis as shown in Fig. 9(b). Moreover, electron diffraction pattern from a thick area is almost same to that of surrounding thin area. Most of fine precipitation in the recovered ferrite area is identified as $\mathrm{Fe}_{2} \mathrm{~W}$ type inter-metallic compound. Slight large precipita- 


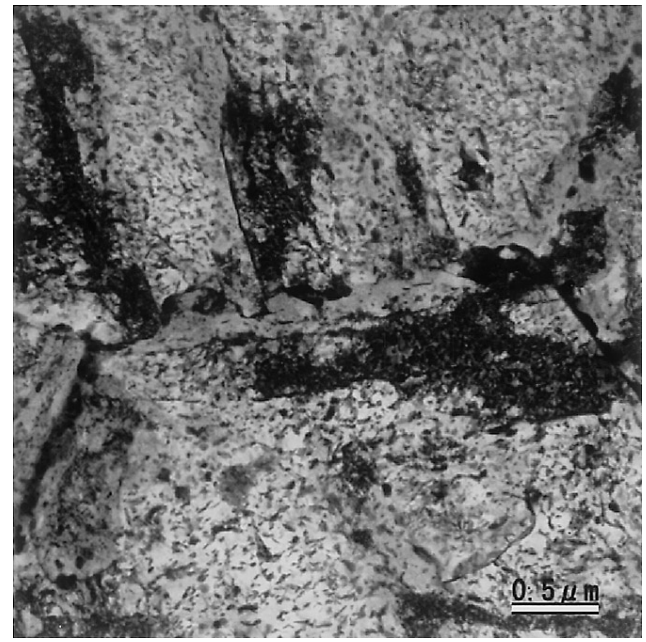

Fig. 8. A TEM micrograph showing uniform distrbution of fine precipitation within matrix observed in the $10 \mathrm{~h}$-aged alloy E.
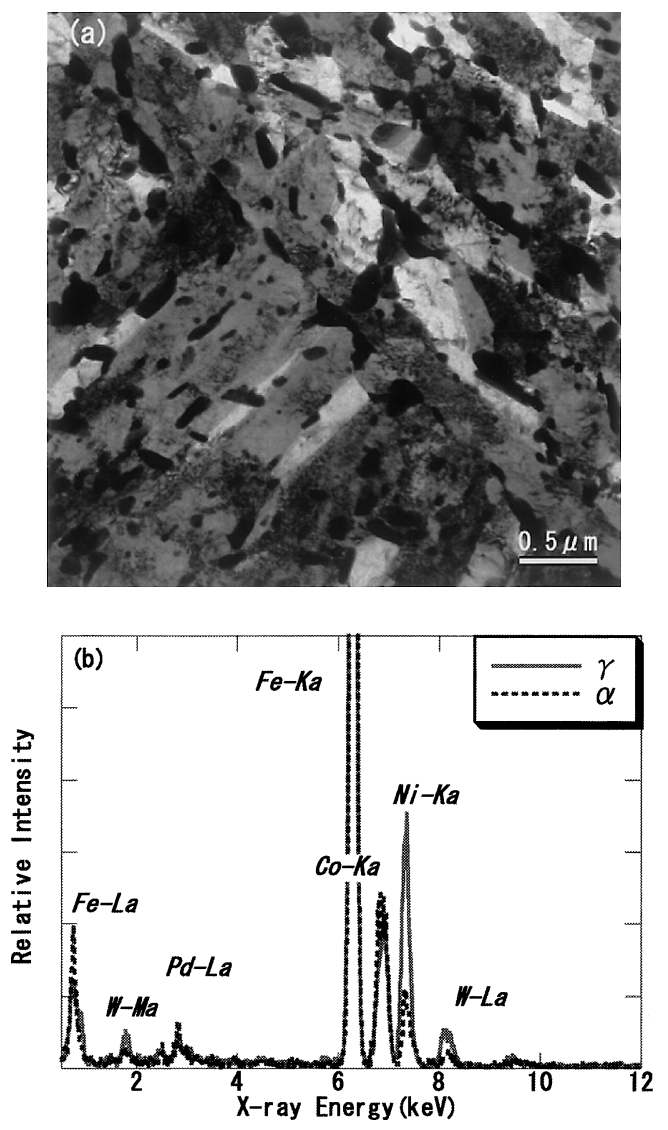

Fig. 9. (a) A TEM micrograph showing the progress of reverse transformation in the $100 \mathrm{~h}$-aged alloy E. (b) Comparison of EDX spectra between a recovered ferrite and a transformed austenite region.

tion is also $\mathrm{Fe}_{2} \mathrm{~W}$ at interfaces of the terrace structure and at prior-austenite grain boundaries. A few $\mathrm{Fe}_{7} \mathrm{~W}_{6}$ type $\mu$ phase and $\mathrm{Fe}(\mathrm{Mn}, \mathrm{Pd})$ is also detected in $\mathrm{Pd}$ added alloy E. Fine precipitates in the reverse transformed region is also thought to be inter-metallic compound such as $\mathrm{Fe}_{2} \mathrm{~W}$ although accurate quantification is difficult due to thick matrix effect in TEM/EDX analysis.

\section{Discussion}

\subsection{Reverse Transformation in C-free Martensitic Alloys}

It has already been studied about reverse transformation in $\mathrm{Fe}-\mathrm{Ni}$ alloys and typical $18 \mathrm{Ni}$-based maraging steels. Krauss and Kessler et al. have reported that this reverse transformation is found to be athermal process for $\mathrm{Fe}-\mathrm{Ni}$ alloys when high heating rate is used., ${ }^{4,5)}$ Goldberg et al. have indicated that a reversion process consists of two or more different types when the dilatometric experiment is conducted with low heating rate for $18 \mathrm{Ni}$-based maraging steels. ${ }^{6}$ Effect of heating rate on this transformation behavior should be explained by the contribution of diffusion process. If the material is kept for long-term at rather low temperature around $773 \mathrm{~K}$, diffusion controlled austenite precipitation can occur. Typical one has been observed in the $18 \mathrm{Ni}$-based maraging steel aged at $773 \mathrm{~K}$ by Araki et al. They have reported that this reverse transformed austenite maintains its crystal structure at room temperature and has K-S relationship with matrix. ${ }^{9)}$ We have also similar results for Alloys B and C aged for $24 \mathrm{~h}$ at $823 \mathrm{~K}$.

According to previous works described above, it is certain that the reverse transformation occurs over $923 \mathrm{~K}$ because $A s$ points are measured ranging from 873 to $973 \mathrm{~K}$ in the C-free martensitic alloys in this study. It is, therefore, essential to clarify the formation mechanism of the characteristic microstructure at high temperature region for better understanding the superior creep properties of these alloy system.

It is necessary to keep the material for long time at low temperature around $773 \mathrm{~K}$ to obtain equilibrium austenite precipitation, which is caused by $\mathrm{Ni}$ fluctuation in matrix during reheating from initial martensitic structure. Such an equilibrium transformation seems to be very difficult since the heating rate is generally high like in the normal aging procedure using an electric furnace. It is, therefore, expected that the austenite phase appears by mainly shearing mechanism without sufficient elemental partitioning in this experiment as many researchers has pointed out. In fact, austenitic region in the materials aged over $923 \mathrm{~K}$ shows continuous plate or lath-like structure with same growing direction macroscopically in a prior-austenite grain. As a result, the specific terrace structure is consisted of the reversely transformed and the recovered region. It is also important that interfaces of this terrace structure are ambiguous in short-term aging and become sharp over $100 \mathrm{~h}$ aging as mentioned in Sec. 3.3. This gradual change in microstructure indicates that a long-range diffusion process is suppressed before heating up to As point.

Figures 10(a) and 10(b) show the mole fraction of equilibrium phase for $\mathrm{Fe}-\mathrm{Ni}-\mathrm{Co}-\mathrm{Mo}, \mathrm{W}$ alloys calculated by Thermo-Calc. at 923 and $973 \mathrm{~K}$, respectively. Increase in the fraction of the austenite phase with $\mathrm{Ni}$ content and temperature is consistent with the results of SEM observations as exemplified in Figs. 5(a) and 5(b). On the other hand, elemental partitioning is not reached to equilibrium during early stages of aging as described in Sec. 3.4. However, there is a very good agreement between calculation and experiment for $1000 \mathrm{~h}$-aged materials given in Table 3 . 

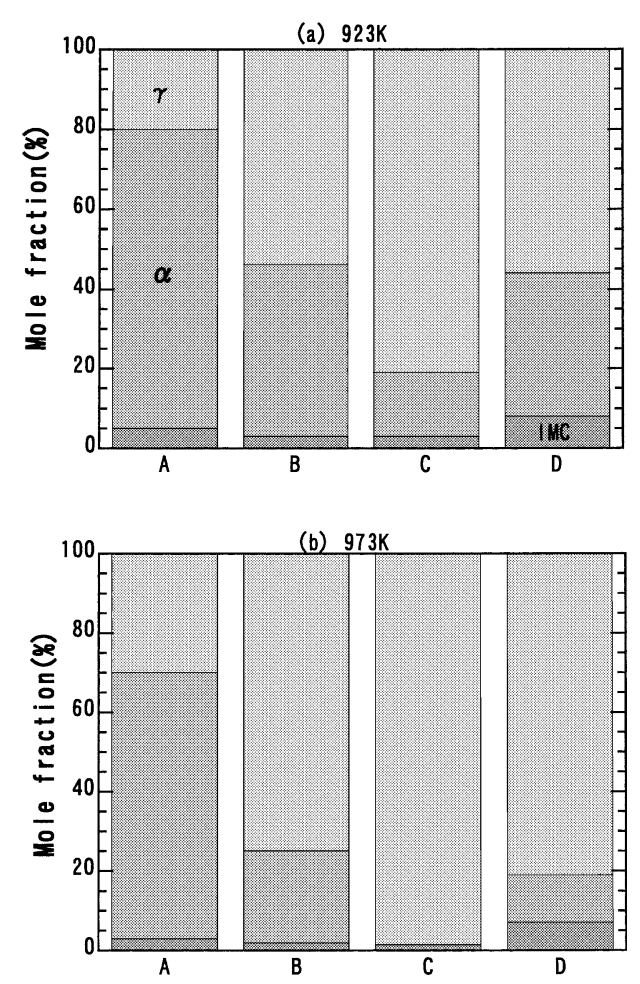

Fig. 10. Mole fraction of the expected equilibrium phases in the alloys A, B, C and D at specific temperatures calculated by Thermo-Calc., (a) is at $923 \mathrm{~K}$ abd (b) is at $973 \mathrm{~K}$, respectively.

Table 3. Partitioning of major elements in different matrix obtained by TEM/EDX analysis and calculation using Thermo-Calc. (mass\%).

\begin{tabular}{|c|c|c|c|c|c|}
\hline \multirow{2}{*}{ TEM/EDX } & & $\mathrm{Fe}$ & $\mathrm{Ni}$ & $\mathrm{Co}$ & $\mathrm{W}$ \\
\cline { 2 - 6 } & Matrix 1 & 77.8 & 6.3 & 13.8 & 2.1 \\
\cline { 2 - 6 } Calculation & Matrix 2 & 70.1 & 20.4 & 7.3 & 2.2 \\
\cline { 2 - 6 } & $\alpha$ & 81.3 & 4.2 & 14.2 & 0.3 \\
\cline { 2 - 6 } & $\gamma$ & 70.0 & 19.9 & 7.0 & 3.1 \\
\hline
\end{tabular}

\subsection{Precipitation Behavior in C-free Martensitic Alloys}

Detail of precipitation behavior in these alloys will be discussed to understand creep strengthening mechanism over $923 \mathrm{~K}$. Many precious works have been done for aging behavior at around $773 \mathrm{~K}$ in the maraging steels by various experimental approaches such as electric resitivity, TEM, Mössbauer spectroscopy, small angle $\mathrm{X}$ ray scattering (SAXS) and calorimetry. ${ }^{10-17)}$ As a result, characteristic microstructure has been clarified and suggested at around $773 \mathrm{~K}$ where $18 \mathrm{Ni}$-based maraging steels show maximum hardness. However, there is not sufficient information about precipitation site and coarsening behavior of inter-metallic compounds such as Laves phase, which becomes dominant over $873 \mathrm{~K}$. In order to know the time dependence of precipitation including low temperature region, the heating curve of DSC measurements exemplified in Fig. 2 is investigated in detail. The first broad exothermic peak locates at around $623-673 \mathrm{~K}$. The second large peak is formed from 723 to $873 \mathrm{~K}$ and continued to an abrupt endothermic reaction. This last endothermic reaction point systematically changes with $\mathrm{Ni}$ content of alloys corresponding to a start of reverse transformation, $A s$.

In the calorimetric measurements by Tokunaga, an exothermic peak was detected at around $623 \mathrm{~K}$ for $\mathrm{Fe}-23 \mathrm{Ni}$ alloy and this reaction was accelerated by Co addition. Same reaction was also confirmed in the $\mathrm{Fe}-18 \mathrm{Ni}-5 \mathrm{Mo}$ based maraging steels. ${ }^{15)}$ Spooner et al. have applied an neutron scattering method to this aging behavior at low temperature and suggested that there is a short-range ordering correlated to Co atoms. ${ }^{18)}$ Then, the first broad peak at low temperature range in our DSC experiments is also thought to be due to the ordering process. However, this modulated structure that is formed at low temperature range is not so important to understand final precipitation because such ordering easily disappears at higher temperatures. It would be better to consider the following process. Takaki et al. have reported that there is an exothermic reaction at $743 \mathrm{~K}$, an endothermic one at $773 \mathrm{~K}$ and another exothermic one at $800 \mathrm{~K}$ in their calorimetric analysis for $18 \mathrm{Ni}$ based maraging alloys. ${ }^{14)}$ It is indicated that the first exothermic reaction corresponds to the formation of Mo cluster within several $\mathrm{nm}$ in diameter by TEM, Mössbauer and SAXS experiments. ${ }^{10-13)}$ Second endothermic peak is thought to be reversion process of this clustering but this process is sometimes unclear due to the following exothermic reaction caused by the formation of stable inter-metallic compounds such as $\mathrm{Ni}_{3} \mathrm{Mo}$ or $\mathrm{Fe}_{2} \mathrm{Mo}$. Almost same change in calorimetric measurements is obtained for the $\mathrm{C}$ free martensitic alloy exemplified in Fig. 2(a). The reason why two exothermic reactions are not well separated in our experiments is higher heating rate than others' experiments. This difference indicates that cluster formation, precipitation of high temperature phase and reverse transformation must be continuously occurred during rapid heating procedure in the case of usual aging experiments or high temperature creep testing. During rapid heating process, precipitation of inter-metallic compounds should take place from cluster without reversion process. Then the distribution of precipitation at early stage of aging becomes uniform when clustering occurs on the dislocations with high density in the initial martensitic structure.

Stable precipitation in these alloys are basically $\mathrm{Fe}_{2}(\mathrm{Mo}, \mathrm{W})$ type Laves phase and $\mathrm{Fe}_{7}(\mathrm{Mo}, \mathrm{W})$ type $\mu$ phase. It is difficult to say which phase is dominant in aged materials from conventional X-ray experiments but most of fine precipitation in matrix seems Laves phase identified by TEM/EDX analysis. Some L1o type $\mathrm{Fe}(\mathrm{Mn}, \mathrm{Pd})$ and $\mathrm{Ni}_{3} \mathrm{Ti}$ are also detected in Pd and Ti added alloys, respectively. Existence of $\mathrm{Ni}_{3} \mathrm{Mo}$ that was often pointed out in the $18 \mathrm{Ni}$ based maraging steels, was not confirmed. It is, therefore, concluded that fine Laves and $\mu$ phase mainly contribute to creep resistance as precipitation strengthening factor in these alloy system.

\subsection{Formation of Microstructure at Creep Tem- perature}

Uniform fine precipitation is observed over the field of view in case of $10 \mathrm{~h}$-aged materials and rapid growing of precipitation at interfaces of terrace structure and its dissolution in the ferrite region are accelerated when aging time is over $100 \mathrm{~h}$ as described in Sec. 3.2. On the other hand, the density of precipitation within the reverse transformed austenite region does not drastically change with aging time. In other words, the initial distribution of precipitation 
(a) As S.T.

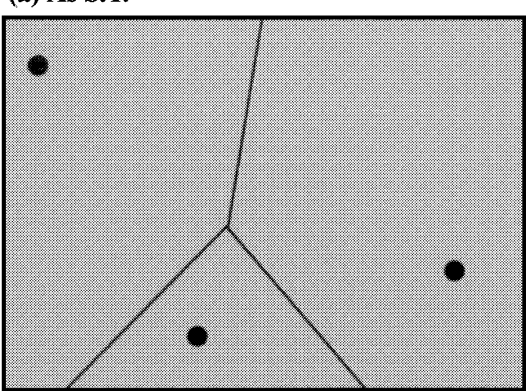

(b) Early stage of aging

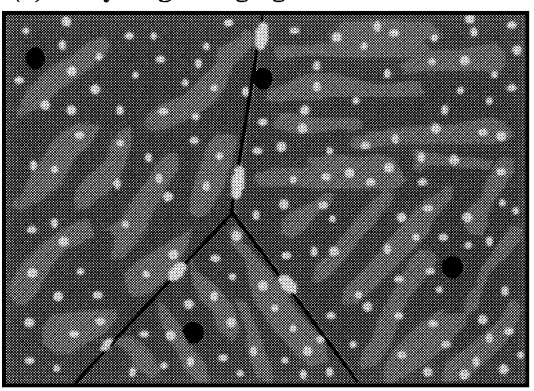

(c) Partitioning of elements during creep

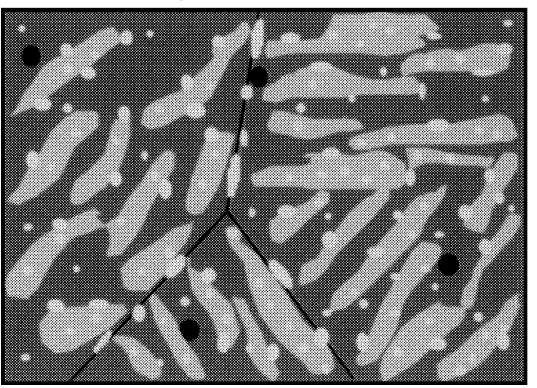

Fig. 11. The schematic change of microstructures in C-free martensitic alloys, (a) is as S.T. condition, (b) is at an early stage of aging or creep over $A_{f}$ point and (c) is later stage after partitioning of elements during longterm keeping at elevated temperatures.

in the austenite region is kept in spite of long-term keeping at high temperature. It is supposed that difference in diffusion rate of solute Mo or W between ferrite and austenite yields such heterogeneous stability of precipitation.

Summarizing precipitation behavior and the reverse transformation kinetics of these alloy systems during heating and the following long-term keeping at high temperatures, schematic change of microstructure can be drawn as shown in Fig. 11. It should be emphasized that characteristic microstructure of these alloys is attained by two continuous processes as follows. Firstly, reverse transformation quickly occurs without sufficient partioning of metallic elements as well as homogeneous nucleation of inter-metallic compounds on dislocations during rapid heating process. Secondly, dissolution of precipitation in ferrite region and its coarsening mainly at terrace interfaces are assisted by diffusion process by long-term keeping at high temperatures.

\section{Conclusion}

In order to understand the origin of superior creep property of C-free martensitic alloys, their microstructure formed at high temperature region was studied from the standpoint of transformation and precipitation behavior. Excellent creep resistance of these alloys at elevated temperatures can be explained by following information about their microstructure.

(1) The complicated matrix structure consists of the recovered ferrite and the reversely transformed austenite over $923 \mathrm{~K}$ at which the superior creep property of these alloys is achieved. This characteristic terrace like structure also contains many fine inter-metallic compounds such as Laves or $\mu$ phase.

(2) The reverse transformation from martensite to austenite occurs without sufficient elemental partitioning when materials are rapidly heated up like in the usual creep experiments.

(3) Elemental partitioning gradually proceeds by longterm keeping over $923 \mathrm{~K}$, then both composition of the ferrite and the austenite almost approach to equilibrium one within $1000 \mathrm{~h}$ aging. The austenite phase at high temperature region transforms into the martensite reversibly with almost the same crystallographic orientation with the surrounding ferrite region.

(4) It is supposed that an initial nucleation of intermetallic compounds such as Laves phase happens rather uniformly on many dislocations in the martensitic structure before reverse transformation. This distribution is gradually changed by the diffusion process during long-term keeping at high temperature.

(5) Frequency of precipitation in the ferrite region becomes low at elevated temperatures but the size of precipitation within austenite region seems to be kept. This means precipitation strengthening of the austenite region is effective even at high temperatures over $923 \mathrm{~K}$.

(6) It is concluded that the existence of the austenite phase that is strengthen by fine stable precipitation is one of important factor for achieving superior creep property over $923 \mathrm{~K}$ of these $\mathrm{C}$-free martensitic alloys.

\section{REFERENCES}

1) S. Muneki, H. Okubo, K. Yamada, M. Igarashi and F. Abe: CAMPISIJ, 13 (2000), 1222.

2) S. Muneki, H. Okubo, K. Yamada, H. Okada, F. Abe and M Igarashi: CAMP-ISIJ, 14 (2001), 1379.

3) S. Muneki, M. Igarashi, K. Yamada, H. Okubo and F. Abe: Proc. of the 7th Int. Conf. on Creep and Fatigue at Elevated Temperatures, The Japan Society of Mechanical Engineers, Tokyo, (2001), 475.

4) G. Krauss: Acta. Metall., 11 (1963), 499.

5) H. Kessler and W. Pitsch: Acta Metall., 15 (1967), 401.

6) A. Goldberg and D.G. O'Connor: Nature, 14 (1967), Jan., 170.

7) K. Hosomi, Y. Ashida, H. Hato, R. Atagi, K. Ishihara and H. Nakamura: Tetsu-to-Hagané, 64 (1978), No. 5, 73.

8) T. Maki, H. Morimoto and I. Tamura: Tetsu-to-Hagané, 65 (1979), No. 10, 1598.

9) T. Araki, H. Masui and K. Shibata: Trans. JIM, 9 (1968), Suppl., 421.

10) D. J. Abson: J. Iron Steel Inst., 208 (1970), 594.

11) A. F. Yedneral: Phys. Met. Metallogr., 33 (1972), No. 2, 89.

12) J. M. Genin: Scr. Metall., 8 (1974), 15.

13) C. Servant: Metall. Trans., 6A (1975), 981.

14) S. Takaki and Y. Tokunaga: J. Jpn. Inst. Met., 44 (1980), 696.

15) Y. Tokunaga and S. Takaki: J. Jpn. Inst. Met., 43 (1979), 834.

16) V. K. Vasudevan: Metall. Trans A, 21A (1990), 2655.

17) U. K. Viswanathan, G. K. Dey and M. K. Asundi: Metall. Trans A, 24A (1993), 2429

18) S. Spooner, H. J. Rack and D. Kalish: Metall. Trans., 2 (1971), 2306. 